\section{Origem social e escolha pelo curso de graduação: inferências a partir de dados do ENADE}

\section{Matheus Monteiro Nascimento e Luciana Massi}

Matheus Monteiro Nascimento

Universidade Federal do Rio Grande do Sul - Porto Alegre, RS, Brasil.

E-mail: matheus.monteiro@ufrgs.br

ORCID: 0000-0001-8179-5391

Luciana Massi

Universidade Estadual Paulista Júlio de Mesquita

Filho - Araraquara, SP, Brasil.

E-mail: Iuciana.massi@unesp.br

ORCID: 0000-0001-8761-3181
Resumo: Neste trabalho analisamos dados de 861 mil estudantes que realizaram o Exame Nacional de Desempenho dos Estudantes entre 2016 e 2018, em relação aos motivos que levam à escolha de um curso de graduação. Realizamos análises estatísticas e adotamos a teoria bourdiana sobre as desigualdades sociais e escolares para interpretar nossos resultados. Identificamos a inserção no mercado e os cursos a distância como motivos nas classes menos favorecidas; a busca por cursos com baixa concorrência, mas valorizados socialmente, nas classes médias; e a escolha por influência familiar ou vocação nas classes altas. Esses resultados confirmam as diferenciações e desigualdades das classes sociais no sistema universitário brasileiro.

Palavras-chave: ENADE; Bourdieu; Classes sociais; Escolha pelo curso. 
Social background and choosing an undergraduate course: inferences from ENADE data
Origen social y elección para oferta acadêmica de grado: inferencias a partir de datos de ENADE
Abstract: In this work, we analyzed data from 861 thousand students who took the National Student Performance Exam between 2016 and 2018, concerning the reasons that lead them to choose an undergraduate course. We performed statistical analyses and adopted Bourdieu's theory on social and school inequalities in order to interpret our results. We identified market insertion and distance-learning courses as reasons for the lower classes; the search for courses with low competition, but socially valued, in the middle classes; and the choice due to family influence or vocation in the upper classes. These results confirm the differences and inequalities of social classes in the Brazilian university system.

Keywords: ENADE; Bourdieu; Social classes; Choosing an undergraduate course.
Resumen: En este trabajo, analizamos datos de 861 mil estudiantes que tomaron el Examen Nacional de Desempeño Estudiantil entre 2016 y 2018, en relación con las razones que llevaron a la elección de una oferta académica de grado. Realizamos análisis estadísticos y adoptamos la teoría de Bourdieu sobre las desigualdades sociales y escolares para interpretar nuestros resultados. Identificamos la inserción en el mercado y los cursos de aprendizaje a distancia como razones para las clases menos favorecidas; la búsqueda de cursos con baja competencia, pero socialmente valorados, en las clases medias; y la elección de influencia familiar o vocación en las clases altas. Estos resultados confirman las diferencias y desigualdades de las clases sociales en el sistema universitario brasileño.

Palabras clave: ENADE; Bourdieu; Clases sociales; Elección de curso de grado. 


\section{Introdução}

O contexto atual de pandemia, provocada pelo novo coronavírus, escancarou diversos aspectos da desigualdade social, com a qual temos convivido há anos. No âmbito educacional, o Governo Federal apostou na manutenção de exames de desempenho como o Exame Nacional de Nível Médio (ENEM) e, no nível superior, o Exame Nacional de Desempenho dos Estudantes (ENADE), possivelmente, considerando que o ensino nas escolas e universidades não tinha sofrido grandes modificações, em função da pandemia. Adotando uma postura completamente meritocrática, ouvimos declarações de que as dificuldades seriam comuns para todos, portanto, a competição continuaria sendo justa'.

Ao contrário da proposta e intenção dos dirigentes políticos e institucionais, o cenário de desigualdade educacional brasileiro tem sido cotidianamente desmascarado pela mídia, explicitando condições muito desiguais de estudo e de relação com a escola. A tese de que o sistema de ensino não promovia oportunidades de democratização, mas reiterava, no nível escolar, desigualdades sociais e estruturais foi enunciada por Bourdieu e Passeron (2009), na década de 60, e continua a ser reiterada até os dias atuais (Bertolin; Marcon, 2015; Bertoncelo, 2016).

Nos últimos anos houve uma forte ampliação na oferta de cursos, modalidades e instituições de ensino, somada à diminuição dos retornos às credenciais escolares, que levou a uma estratificação horizontal ou democratização segregativa (Duru-Bellat, 2006; Bertoncelo, 2016; Crepalde; Silveira, 2016). O conceito remete ao fato de que rendimentos muito distintos passaram a ser identificados, pela literatura sociológica, em função do tipo de diploma obtido, além do patrimônio cultural, econômico e social da família, que estava sendo camuflado por uma suposta ampliação de oportunidades iguais para todos os estudantes. Essas supostas oportunidades e rentabilidade dos diplomas, associada a uma efetiva política de ampliação de vagas no Ensino Superior, aumentou significativamente a procura por esse nível de ensino - que passou de 1 para 8,5 milhões de matriculados, entre 2000 e 2018, segundo o Censo da Educação Superior realizado pelo Instituto Nacional de Estudos e Pesquisas Educacionais Anísio Teixeira (Inep). Resta saber quais são as motivações que levaram a esse aumento e como elas se manifestam em diferentes classes sociais?

Nesse contexto, o ENADE representa uma importante fonte de dados para o estudo e a compreensão dessas desigualdades no nível superior. Constituído por questões de conhecimentos gerais e específicas, questionário do estudante e questionário de percepção do aluno sobre a prova, é possível extrair dos microdados do ENADE informações sobre o perfil do estudante e suas relações com o nível superior. Neste estudo, analisamos especificamente os motivos associados à escolha pelo curso de graduação em relação ao pertencimento de classe, pautados na teoria da reprodução bourdiana. Considerando este enfoque no ENADE, apresentamos nas duas seções a seguir uma breve revisão bibliográfica visando contextualizar esse exame e destacar os resultados de pesquisas que se aproximam de nosso objeto: as desigualdades sociais no Ensino Superior. Ressaltamos que a

\footnotetext{
${ }^{1}$ De acordo com afirmação do antigo Ministro da Educação Abraham Weintraub (Alfano, 2020).
} 
investigação sobre os motivos associados à escolha pelo curso de graduação é uma abordagem original, uma vez que não encontramos em todo Portal de Periódicos Capes outra pesquisa sobre esse tema no ENADE.

\section{O ENADE como política de avaliação do Ensino Superior brasileiro}

O ENADE se insere no Sistema Nacional de Avaliação da Educação Superior (SINAES) junto com a Avaliação Institucional e Avaliação dos Cursos de Graduação organizados pelo Inep. Ele foi criado em 2004, substituindo o antigo Provão ou Exame Nacional de Cursos, com a promessa de superar diversos problemas daquela que foi a primeira avaliação de larga escala no Ensino Superior (Brasil, 2004; Verhine; Dantas; Soares, 2006; Brito, 2008; Bertolin; Marcon, 2015). A avaliação do Ensino Superior foi implementada, gradualmente, a partir da década de 90 - conhecida como "Década da Avaliação" - em um contexto internacional, de globalização e neoliberalismo, e político, de "gerenciamento à distância" ou "reformismo do Estado" ou "Estado avaliador" (Verhine; Dantas; Soares, 2006; Canan; Eloy, 2016; Feldman; Souza, 2016). Resumidamente, o Estado diminuía sua participação e responsabilização direta por ações educacionais passando a orientá-las e acompanhá-las, principalmente, por meio da avaliação.

Os principais aspectos que o ENADE pretendia superar, em relação ao Provão (fortemente criticado pela comunidade acadêmica), eram 1) introduzir um modelo de avaliação dinâmica, que acompanhava o aluno do ingresso à saída do ensino superior; 2) ampliar as dimensões de avaliação para cumprir um papel formativo para as instituições e não só aferir o desempenho dos alunos e ranquear instituições; 3) reduzir custos de aplicação da prova por meio de técnicas de amostragem (Brito, 2008; Verhine; Dantas; Soares, 2006; Soares et al., 2018). Por outro lado, ele manteve alguns limites como 1) a adoção de testes referenciados a critério, que não permitem uma comparação equitativa do desempenho de diferentes cursos e instituições; 2) a obrigatoriedade da realização do exame, por parte do aluno, desvinculada de qualquer implicação sobre seu desempenho (lowstake), que gera uma cultura de descompromisso com o exame; e 3) permaneceu sendo usado como instrumento de ranqueamento de instituições (Brito, 2008; Verhine; Dantas; Soares, 2006). Além disso, com o tempo o teste deixou de ser aplicado aos ingressantes, perdendo seu potencial de acompanhar a aprendizagem dos estudantes e não apenas o produto final de sua formação.

Inserido no âmbito das avaliações de larga escala, o ENADE também reproduz alguns problemas decorrentes do aspecto high stakes (Verhine; Dantas; Soares, 2006) ou de responsabilização (Bonamino; Souza, 2012) que vem sendo denunciado na Educação Básica. Segundo Bonamino e Souza (2012) é possível identificar três gerações de avaliação de larga escala que apresentam uma progressão em termos de responsabilização. A partir da segunda geração observouse a inclusão da bonificação meritocrática por bons resultados (adotada pelo Estado de São Paulo) ou a bonificação como forma de melhoria da condição das escolas com mais dificuldades (implementada em Pernambuco) (Bonamino; Souza, 2012). A partir da terceira geração fica mais presente um estreitamento do currículo escolar que passa a ser determinado pela avaliação de larga escala

\section{8}


(Bonamino; Souza, 2012). No Ensino Superior, observamos o interesse de estudantes pelos cursos e universidades, em um contexto empresarial de mercado (Bertolin; Marcon, 2015), como substituto da bonificação que, assim como nas escolas, leva, na universidade, a uma valorização e investimento em cursos preparatórios para os alunos que realizam o ENADE. Por outro lado, há pouca influência do exame no currículo, uma vez que esses cursos costumam ser apresentados apenas seis meses antes do exame, além dos resultados da prova serem fracamente convertidos em políticas institucionais de revisão e melhoria dos cursos (Canan; Eloy, 2016). Observa-se, assim que a avaliação não cumpre seu objetivo, pois, como afirmam Soares e colaboradores (2018, p. 27), o "valor de uma avaliação é expresso na utilização de seus resultados", ou seja, o ENADE tende a se reduzir a uma avaliação de desempenho discente e institucional.

\section{Estudos sobre perfil e desempenho pautados nos microdados do ENADE}

Lima e colaboradores (2019) realizaram uma revisão bibliográfica sistemática sobre ENADE e ENEM no "Google Acadêmico". Os autores localizaram 39 pesquisas sobre o exame de nível superior, publicadas entre 2005 e 2016. Esses estudos tinham como objetivo: avaliar o conteúdo da prova (4); o desempenho dos estudantes no exame (19); testar ou desenvolver ferramentas para analisar o exame (5); investigar a forma como o exame é estruturado (3); analisar a formação do docente e relacioná-la com o desempenho dos estudantes nas provas (5); e analisar a gestão e acesso ao Ensino Superior (4) (Lima et al., 2019). Segundo Lima e colaboradores (2019), a maioria dos autores usou análise estatística descritiva - só um estudo empregou mineração de dados nas notas do ENADE - com base nos seguintes dados: nota do ENADE (16); questionário socioeconômico (10); conteúdo da prova (8); conceito do ENADE (8); questionário do coordenador (1) e questionário de percepção do estudante (4) (Lima et al., 2019). Os autores concluem que esses estudos são limitados, por usarem, principalmente, estatística descritiva para analisar dados socioeconômicos e notas dos exames.

Assim como neste artigo, as relações entre classes sociais e desempenho no ENADE também foram estudadas por um conjunto de autores (Brito, 2007; Beltrão; Mandarino, 2014; Bertolin; Marcon, 2015; Crepalde; Silveira, 2016; Gualberto; Rodrigues, 2017; Wainer; Melguizo, 2018). Bertolin e Marcon (2015) adotam o conceito de capital cultural de Bourdieu, resultados de pesquisas nacionais e do exterior e realizam cruzamentos simples, com os dados agrupados do ENADE, para mostrar que, assim como a pesquisa sociológica denuncia desde a década de 60, o background familiar (origem social, renda, escolarização dos pais) explica muito mais o desempenho do que o "efeito escola" (infraestrutura institucional, qualidade dos professores, etc.). Diante disso, os autores refutam a possibilidade de ranqueamento de instituições a partir do ENADE, defendendo que ele só seria justo e possível caso comparasse apenas alunos que tiveram as mesmas condições sociais e formativas, ou seja, o mesmo capital cultural. Nesse sentido, Beltrão e Mandarino (2014) mostram, a partir dos dados dos participantes do ENADE de 2004 a 2011, o resultado de uma Análise de Componentes Principais cujo fator afluência socioeconômica - composto por escolaridade dos pais, escola onde o aluno concluiu o

\section{9}


ensino médio e renda familiar - destaca níveis mais baixos nos cursos de formação de professores e níveis mais altos nos cursos de Arquitetura e Urbanismo, Relações Internacionais e Medicina.

Identificamos estudos focados especificamente em cursos de licenciatura que destacam o perfil socioeconômico pouco favorecido dos alunos e predominância de estudantes em cursos noturnos de instituições privadas (Brito, 2007), bem como a baixa influência da dedicação dos alunos ao trabalho em paralelo ao estudo em seu desempenho na prova (Gualberto; Rodrigues, 2017). Outro tipo de enfoque é nas variáveis que podem impactar no desempenho, considerando cursos e períodos específicos, em que destaca-se a grande variação de desempenho entre as instituições e o impacto do corpo docente e da infraestrutura no desempenho (Lemos; Miranda, 2015). A questão do desempenho dos cotistas também é investigada por alguns autores, merecendo destaque o estudo de Wainer e Melguizo (2018) sobre os cotistas, os bolsistas do Prouni e os beneficiários do FIES. Os autores destacam um conjunto de limitações metodológicas das pesquisas sobre as políticas de inclusão e, por meio das notas do ENADE de 2012 a 2014, constatam que não há diferença de desempenho entre esses estudantes e seus colegas de classe (mesma instituição, curso e ano).

Nesse mesmo sentido, recuperando as discussões sobre o efeito escola, Crepalde e Silveira (2016) e Lemos e Miranda (2015) destacam que as desigualdades socioeconômicas têm menor impacto quando se considera a diferenciação entre as instituições e os cursos. Assim, Crepalde e Silveira (2016) denunciam a estratificação horizontal revelada no ENADE, em que a diversidade de ofertas no Ensino Superior esconde as efetivas chances de ascensão social, uma vez que determinadas áreas e instituições mais concorridas tendem a apresentar melhores resultados por já receber alunos mais preparados. Eles ressaltam que esse cenário não mudou com a ampliação de vagas e oportunidades, pois "o ensino superior também cria e recria mecanismos de diferenciação" (Crepalde; Silveira, 2016, p. 235).

Não identificamos estudos que investiguem, nos dados de todos os cursos do ENADE, as possíveis diferenciações e desigualdades das classes sociais em relação aos motivos que levam à escolha de um curso de graduação. Uma exceção é o trabalho de Brito (2007) sobre a razão da opção pela licenciatura, investigada a partir de dados do ENADE 2005, que contemplam questões específicas sobre essa modalidade de curso. A autora identificou nas licenciaturas um perfil socioeconômico menos privilegiado e a prevalência de estudantes de cursos noturnos e à distância - que, tradicionalmente, representam formações menos qualificadas no Brasil. Além disso, percebeu que o interesse em seguir carreira docente, em torno de $70 \%$ dos concluintes, aumentou quando comparou as respostas dos ingressantes e concluintes dos cursos e variou muito, com níveis mais altos entre os que optaram pela pedagogia e mais baixos nos que escolheram outras licenciaturas. Ainda sobre a atratividade da carreira docente, Gatti (2009) percebeu uma forte associação entre essa escolha, pouco frequente entre jovens do Ensino Médio e pouco valorizada socialmente, e as classes sociais menos favorecidas. Na área de matemática, Beltrão e Mandarino (2014) investigaram a efetiva inserção profissional dos concluintes do ENADE e perceberam que a opção pelo magistério é prioritária entre as mulheres e que muitos egressos atuam em atividades de nível médio ou não afins com a área. Esses poucos dados

\section{0}


apontam para relações de classe entre a opção pelo curso superior e a rentabilidade dos diplomas, tema que foi estudado por Bourdieu e será brevemente discutido a seguir.

\section{A causalidade do provável de Bourdieu e a escolha pelo Ensino Superior}

Além de ter formulado uma consistente teoria sobre a reprodução escolar das desigualdades sociais, Bourdieu $(1983,2015)$ formulou o conceito de habitus e de capital cultural para explicar as escolhas dos agentes em relação ao sistema escolar. As desigualdades escolares são explicadas a partir da identificação da existência de um capital cultural considerado legítimo, por ser o capital que a classe dominante detém (Bourdieu, 2007). Esse capital é exigido na escola sem que tenha sido efetivamente ensinado ou transmitido pela família para os membros das classes dominadas (Bourdieu; Passeron, 2009). O capital cultural se manifesta na forma de conhecimentos, competências, posse de objetos e títulos, sendo que os legítimos representam uma vantagem significativa no sistema escolar (Bourdieu, 2015).

O habitus está indiretamente relacionado ao capital cultural, pois ele também se refere a diferenças de classe que produzem distintas formas de percepção, apreciação, práticas e comportamentos sociais. Esse conjunto se organiza em um sistema de disposições que derivam da incorporação das estruturas passadas e orienta as ações futuras dos agentes. Bourdieu (2015) afirma, assim como Jessé de Souza (2018) estudando o contexto brasileiro atual, que nem todas as classes desenvolvem disposições estratégicas para planejar seu futuro. Assim, as "práticas engendradas pelo habitus são ajustadas" às condições objetivas, que "se definem por uma relação específica entre mecanismos, tais como o mercado de trabalho ou o mercado escolar" (Bourdieu, 2015, p. 100). Representando a "inércia do grupo", é o habitus que explica a "causalidade do provável" (Bourdieu, 2015, p. 123-125), ou seja, a tendência a vislumbrar como possível e desejável apenas aquilo que está disponível para sua classe.

Os agentes com menor volume de capital cultural tendem a empregar estratégias de curto prazo e de curto alcance, ou seja, fazerem maus investimentos escolares. As classes populares, "não podendo vislumbrar para os filhos um futuro diferente de seu próprio presente", tendem a investir pouco na sua escolarização e apostar em formações mais curtas diretamente voltadas para o mercado de trabalho (Bourdieu, 2015, p. 109). As classes médias, costumam apostar mais no sistema de ensino, eventualmente, como única forma de ascensão social e tendem a "fazer investimentos escolares desproporcionados aos seus recursos". Por sua vez, as classes dominantes detêm alto volume de capital cultural, econômico e social, que permitem maximizar o "rendimento escolar e simbólico dos certificados escolares no mercado de trabalho" e "minimizar as perdas em caso de fracasso" (Bourdieu, 2015, p. 104).

Bourdieu (2015, p. 104) afirma, ainda, que os "mais desprovidos não são capazes de descobrir os ramos mais cotados [...] senão com atraso, quando já estariam desvalorizados", essa desvalorização, muitas vezes, é decorrente do "simples fato de ter se tornado acessível aos menos 
favorecidos". Com base nessas considerações analisamos os dados do ENADE quanto à motivação em cursar determinado curso de nível superior.

\section{Metodologia}

O ENADE é realizado anualmente e organizado por ciclos que determinam as áreas do conhecimento - e cursos - a serem avaliadas em cada edição do exame. Existem basicamente três áreas diferentes e a cada ano uma área é avaliada. A lista completa com as áreas pode ser encontrada no site do Inep (2020a).

Para a efetivação de uma pesquisa que queira captar as propriedades sociais que mais se relacionam com a motivação para cursar determinado curso do Ensino Superior, portanto, é preciso analisar os últimos três anos de realização do ENADE. Essa foi a estratégia adotada no presente trabalho. Selecionamos os dados dos últimos três anos do exame com dados disponíveis, 2018, 2017 e 2016. Todos os dados são abertos e disponibilizados também na página do Inep (2020b). Nestas planilhas são encontradas informações sobre o estudante e seu desempenho nas provas, sobre a sua instituição e sobre o curso.

Separados os estudantes dos três anos foi aplicado um único filtro na amostra de dados a fim de eliminar aqueles que tenham deixado de responder algum dos itens do questionário. Com isso, nossa amostra foi constituída de um total de 861 mil alunos de graduação do país. Toda as análises foram realizadas no ambiente de programação $R$ (Team, 2000).

A tabela 1 apresenta a distribuição dos estudantes que compõem a amostra em relação ao sexo, renda, categoria administrativa da instituição de ensino superior a qual o aluno pertence, região desta instituição, nível de instrução da mãe e do pai.

Tabela 1: Perfil da amostra de estudantes que fizeram o ENADE em 2016, 2017 e 2018

\begin{tabular}{|c|c|c|c|c|c|c|}
\hline & Sexo & Renda & Instituição & Região & Inst. Mãe & Inst. Pai \\
\hline Feminino & 520039 & & & & & \\
\hline Masculino & 341613 & & & & & \\
\hline Até $1,5 \mathrm{SM}$ & & 188758 & & & & \\
\hline De 1,5 a $3 \mathrm{SM}$ & & 245120 & & & & \\
\hline De 3 a 4,5 SM & & 172845 & & & & \\
\hline $\mathrm{De} 4,5$ a $6 \mathrm{SM}$ & & 96759 & & & & \\
\hline De 6 a 10 SM & & 91234 & & & & \\
\hline De 10 a 30 SM & & 56299 & & & & \\
\hline Mais de $30 \mathrm{SM}$ & & 10642 & & & & \\
\hline
\end{tabular}

$\begin{array}{cc}\text { Privada c/ fins lucrativos } & 348792 \\ \text { Privada s/ fins lucrativos } & 278150 \\ \text { Pública Municipal } & 12279 \\ \text { Pública Estadual } & 71284 \\ \text { Pública Federal } & 151152\end{array}$

Região Norte (NO)

Região Nordeste (NE)

57254

168817

385336 


\begin{tabular}{|c|c|c|}
\hline Região Sul (SUL) & 180526 & \\
\hline Região Centro-Oeste (CO) & 69724 & \\
\hline Nenhuma & 50888 & 69942 \\
\hline Fundamental 1 & 207731 & 244580 \\
\hline Fundamental 2 & 124642 & 127032 \\
\hline Ensino Médio & 273631 & 258169 \\
\hline Ensino Superior & 130977 & 119365 \\
\hline Pós-graduação & 73788 & 42569 \\
\hline
\end{tabular}

Fonte: Dados da pesquisa.

Todas estas características foram cruzadas com a pergunta do questionário que inferia o Motivo pela Escolha do Curso de Graduação (MOTIVO). Os resultados desses entrecruzamentos foram dispostos em tabelas de frequência e serão detalhados na próxima seção.

Para investigar em maior detalhamento de que maneira a classe social dos estudantes se relaciona com a decisão pelo curso, foi utilizado como recurso metodológico a Análise de Correspondências Múltiplas (ACM). Esta ferramenta permite, a partir de dados categóricos, posicionar agentes ou propriedades sociais em mapas bidimensionais (Kluger, 2018). A distância entre os pontos no mapa revela o grau de associação entre as variáveis (Greenacre, 2017). Quer dizer, quanto mais próximos/afastados dois pontos estiverem maior/menor a associação entre as variáveis que estão dispostas no mapa. Este tipo de análise popularizou-se com os trabalhos de Bourdieu, tornando-se o método mais recorrente nas obras do sociólogo. Bourdieu privilegiou as ACM nas suas pesquisas justamente pela possibilidade de representação gráfica semelhante a sua concepção estrutural e relacional do espaço (Kluger, 2018). No campo educacional brasileiro, as ACM foram o recurso utilizado para analisar a educação superior do país (Hey, 2008), para investigar as desigualdades educacionais no município de São Paulo (Perosa; Lebaron; Leite, 2015), para evidenciar as desigualdades de acesso ao Ensino Superior público brasileiro (Nascimento; Cavalcanti; Ostermann, 2018) e para estudar as hierarquias sociais dos pesquisadores orientadores da área de Ensino da CAPES (Massi; Carvalho; Giordan, 2020).

Considerando que o principal objetivo do trabalho é entender os motivos associados à escolha pelo curso de graduação em relação ao pertencimento de classe, foi realizada uma ACM cruzando a classe social com a variável MOTIVO. Para esta análise, criamos uma nova variável que serve de indicativo da classe social. Diferentemente do que é realizado pelo IBGE, não definimos classe social apenas pela renda. Utilizamos também a instrução dos pais como marcador de classe, recurso recorrente em análises sociológicas (Souza, 2018) e coerente com a perspectiva de Bourdieu (2007). Assim, as variáveis renda, instrução da mãe e instrução do pai foram unificadas na variável Nível Socioeconômico (NSE), estruturada em cinco níveis: Muito Baixo, Baixo, Médio, Alto e Muito Alto. Esta construção foi realizada a partir de uma análise de agrupamentos. Para um maior detalhamento sobre este processo o trabalho de Nascimento, Cavalcanti e Ostermann (2018) pode ser consultado. 


\section{Resultados e discussões}

O item do questionário que infere o motivo pela escolha do curso (Qual o principal motivo para você ter escolhido este curso?) e que sinteticamente chamamos de variável MOTIVO, permite oito possíveis respostas: inserção no mercado de trabalho, influência familiar, valorização profissional, prestígio social, vocação, oferecido na modalidade a distância, baixa concorrência para ingresso ou outro motivo. A tabela 2 mostra a distribuição de frequência em proporção das variáveis descritas anteriormente para cada uma destas possibilidades de resposta.

Tabela 2: Proporção entre variáveis categóricas do questionário

\begin{tabular}{|c|c|c|c|c|c|c|c|c|c|}
\hline & & $\begin{array}{c}\text { Inserção } \\
\text { no } \\
\text { mercado }\end{array}$ & $\begin{array}{l}\text { Influência } \\
\text { familiar }\end{array}$ & $\begin{array}{l}\text { Valorização } \\
\text { profissional }\end{array}$ & $\begin{array}{c}\text { Prestígio } \\
\text { social }\end{array}$ & Vocação & $\begin{array}{c}\text { Oferecido } \\
\text { a } \\
\text { distância }\end{array}$ & $\begin{array}{c}\text { Baixa } \\
\text { concorrência }\end{array}$ & $\begin{array}{l}\text { Outro } \\
\text { motivo }\end{array}$ \\
\hline \multirow{2}{*}{ 恼 } & Feminino & $23,6 \%$ & $7,6 \%$ & $11,9 \%$ & $1,0 \%$ & $36,2 \%$ & $1,8 \%$ & $0,9 \%$ & $16,9 \%$ \\
\hline & Masculino & $24,7 \%$ & $6,0 \%$ & $16,5 \%$ & $1,4 \%$ & $35,2 \%$ & $1,2 \%$ & $0,9 \%$ & $14,0 \%$ \\
\hline \multirow{7}{*}{$\begin{array}{l}\frac{\pi}{0} \\
\frac{\sigma}{0} \\
\simeq\end{array}$} & Até $1,5 \mathrm{SM}$ & $28,2 \%$ & $6,4 \%$ & $10,7 \%$ & $1,1 \%$ & $34,2 \%$ & $1,6 \%$ & $1,3 \%$ & $16,5 \%$ \\
\hline & De 1,5 a $3 S M$ & $23,6 \%$ & $6,5 \%$ & $13,4 \%$ & $1,1 \%$ & $36,1 \%$ & $1,8 \%$ & $1,0 \%$ & $16,5 \%$ \\
\hline & De 3 a 4,5 SM & $23,7 \%$ & $6,8 \%$ & $15,3 \%$ & $1,1 \%$ & $35,3 \%$ & $1,6 \%$ & $0,8 \%$ & $15,5 \%$ \\
\hline & De 4,5 a 6 SM & $22,3 \%$ & $7,3 \%$ & $15,8 \%$ & $1,1 \%$ & $36,5 \%$ & $1,5 \%$ & $0,7 \%$ & $14,9 \%$ \\
\hline & De 6 a 10 SM & $22,0 \%$ & $7,6 \%$ & $16,0 \%$ & $1,2 \%$ & $36,5 \%$ & $1,5 \%$ & $0,6 \%$ & $14,7 \%$ \\
\hline & De 10 a 30 SM & $20,4 \%$ & $9,2 \%$ & $14,4 \%$ & $1,2 \%$ & $38,8 \%$ & $1,0 \%$ & $0,5 \%$ & $14,6 \%$ \\
\hline & Mais de 30 SM & $20,1 \%$ & $13,7 \%$ & $12,7 \%$ & $1,7 \%$ & $38,2 \%$ & $0,3 \%$ & $0,2 \%$ & $13,0 \%$ \\
\hline \multirow{5}{*}{ 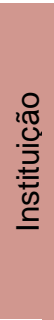 } & $\begin{array}{l}\text { Privada } \mathrm{c} \text { fins } \\
\text { lucrativos }\end{array}$ & $25,3 \%$ & $7,0 \%$ & $16,0 \%$ & $1,2 \%$ & $34,2 \%$ & $2,2 \%$ & $0,3 \%$ & $13,9 \%$ \\
\hline & $\begin{array}{l}\text { Privada s/ fins } \\
\text { lucrativos }\end{array}$ & $23,9 \%$ & $7,8 \%$ & $14,2 \%$ & $1,2 \%$ & $37,1 \%$ & $1,0 \%$ & $0,3 \%$ & $14,5 \%$ \\
\hline & $\begin{array}{l}\text { Pública } \\
\text { Municipal }\end{array}$ & $23,4 \%$ & $9,1 \%$ & $13,3 \%$ & $1,5 \%$ & $36,1 \%$ & $0,4 \%$ & $0,3 \%$ & $15,9 \%$ \\
\hline & Pública Estadual & $24,0 \%$ & $6,7 \%$ & $10,3 \%$ & $1,0 \%$ & $34,0 \%$ & $1,1 \%$ & $2,4 \%$ & $20,5 \%$ \\
\hline & Pública Federal & $21,6 \%$ & $5,5 \%$ & $9,5 \%$ & $1,0 \%$ & $37,9 \%$ & $1,4 \%$ & $2,8 \%$ & $20,3 \%$ \\
\hline \multirow{5}{*}{ : } & $\begin{array}{l}\text { Região Norte } \\
\text { (NO) }\end{array}$ & $26,6 \%$ & $8,7 \%$ & $15,0 \%$ & $1,3 \%$ & $31,1 \%$ & $0,8 \%$ & $1,5 \%$ & $15,0 \%$ \\
\hline & $\begin{array}{c}\text { Região } \\
\text { Nordeste (NE) }\end{array}$ & $22,3 \%$ & $7,3 \%$ & $11,6 \%$ & $1,0 \%$ & $38,5 \%$ & $0,8 \%$ & $1,4 \%$ & $17,1 \%$ \\
\hline & $\begin{array}{l}\text { Região Sudeste } \\
\text { (SE) }\end{array}$ & $23,8 \%$ & $6,4 \%$ & $14,4 \%$ & $1,2 \%$ & $36,8 \%$ & $1,3 \%$ & $0,7 \%$ & $15,4 \%$ \\
\hline & $\begin{array}{l}\text { Região Sul } \\
\text { (SUL) }\end{array}$ & $25,3 \%$ & $7,1 \%$ & $14,7 \%$ & $1,1 \%$ & $32,9 \%$ & $3,0 \%$ & $0,7 \%$ & $15,2 \%$ \\
\hline & $\begin{array}{l}\text { Região Centro- } \\
\text { Oeste (CO) }\end{array}$ & $24,4 \%$ & $8,1 \%$ & $12,2 \%$ & $1,4 \%$ & $34,8 \%$ & $1,5 \%$ & $1,0 \%$ & $16,5 \%$ \\
\hline \multirow{6}{*}{ 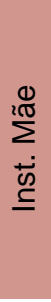 } & Nenhuma & $40,3 \%$ & $3,5 \%$ & $13,4 \%$ & $0,9 \%$ & $25,0 \%$ & $2,9 \%$ & $0,8 \%$ & $13,2 \%$ \\
\hline & Fundamental 1 & $24,3 \%$ & $5,3 \%$ & $16,2 \%$ & $1,1 \%$ & $33,5 \%$ & $2,8 \%$ & $1,0 \%$ & $15,9 \%$ \\
\hline & Fundamental 2 & $24,0 \%$ & $6,0 \%$ & $14,6 \%$ & $1,2 \%$ & $35,4 \%$ & $1,6 \%$ & $0,9 \%$ & $16,2 \%$ \\
\hline & Ensino Médio & $23,0 \%$ & $7,3 \%$ & $13,2 \%$ & $1,2 \%$ & $37,0 \%$ & $1,0 \%$ & $1,0 \%$ & $16,2 \%$ \\
\hline & Ensino Superior & $21,6 \%$ & $9,5 \%$ & $11,8 \%$ & $1,2 \%$ & $39,1 \%$ & $0,7 \%$ & $0,8 \%$ & $15,4 \%$ \\
\hline & Pós-graduação & $20,8 \%$ & $10,3 \%$ & $11,1 \%$ & $1,1 \%$ & $39,8 \%$ & $0,8 \%$ & $0,7 \%$ & $15,4 \%$ \\
\hline \multirow{6}{*}{$\begin{array}{l}\overline{\widetilde{\sigma}} \\
\dot{0} \\
\stackrel{\dot{\omega}}{=}\end{array}$} & Nenhuma & $35,9 \%$ & $4,2 \%$ & $12,8 \%$ & $0,9 \%$ & $27,5 \%$ & $2,6 \%$ & $1,0 \%$ & $14,9 \%$ \\
\hline & Fundamental 1 & $24,1 \%$ & $5,9 \%$ & $15,4 \%$ & $1,1 \%$ & $33,9 \%$ & $2,5 \%$ & $1,0 \%$ & $16,0 \%$ \\
\hline & Fundamental 2 & $23,6 \%$ & $6,7 \%$ & $14,0 \%$ & $1,2 \%$ & $36,1 \%$ & $1,4 \%$ & $0,9 \%$ & $16,1 \%$ \\
\hline & Ensino Médio & $22,8 \%$ & $7,4 \%$ & $13,2 \%$ & $1,2 \%$ & $37,6 \%$ & $0,9 \%$ & $0,9 \%$ & $15,9 \%$ \\
\hline & Ensino Superior & $21,5 \%$ & $9,3 \%$ & $12,4 \%$ & $1,2 \%$ & $38,7 \%$ & $0,8 \%$ & $0,8 \%$ & $15,3 \%$ \\
\hline & Pós-graduação & $20,2 \%$ & $10,1 \%$ & $11,7 \%$ & $1,1 \%$ & $40,3 \%$ & $0,8 \%$ & $0,6 \%$ & $15,2 \%$ \\
\hline
\end{tabular}

Fonte: Dados da pesquisa. 
A realização do teste qui-quadrado $\left(x^{2}\right)$ mostra que todas as categorias se correlacionam significativamente $(p<0,05)$ com as categorias da variável MOTIVO. Em outras palavras, existe associação entre o sexo, a renda, a dependência administrativa da instituição, a região, a instrução da mãe e do pai com a motivação em cursar determinado curso de nível superior. Para facilitar as análises foram destacadas aquelas categorias que mais contribuíram com valor do qui-quadrado, ou seja, aquelas que apresentaram maior variação entre os grupos da mesma categoria de resposta. Por exemplo, a variável sexo apresentou maior variação entre Feminino e Masculino na categoria de resposta Valorização profissional e, por isso, foi destacada.

Em relação à renda, nota-se que a influência familiar é um motivo para escolha do curso de graduação mais frequente entre os estudantes de renda mais elevada, enquanto a inserção no mercado de trabalho mais frequente entre os alunos de baixa renda. No que diz respeito à instituição, percebe-se que estudantes das privadas buscam com o curso de graduação uma maior valorização profissional do que estudantes de instituições públicas. Este cenário se inverte no que diz respeito à concorrência. Estudantes das instituições públicas apontam a baixa concorrência como principal motivo para escolha do curso em uma proporção muito maior do que alunos das instituições de dependência privada.

Sobre as regiões do país, há diferenças importantes na escolha por cursos a distância, muito mais frequente na região Sul do que nas outras; e na baixa concorrência dos cursos oferecidos em instituições do Centro-Oeste, do Norte e do Nordeste.

A instrução dos pais apresentou resultado semelhante para ambos, mãe e pai. Estudantes com pais de baixo nível instrucional tendem a escolher o curso de graduação pela possibilidade de inserção no mercado de trabalho e a possibilidade de cursar a distância. Já os alunos com pais de elevado nível de instrução indicam que escolheram o curso pela influência dos pais e por vocação em maior proporção do que alunos com pais de instrução mais baixa.

Para melhor compreender esta relação entre origem social e o motivo de escolha pelo curso de graduação realizamos a ACM. O resultado da análise está apresentado na imagem 1. A representação espacial produzida pela ACM explicita as hierarquias sociais que remetem a estruturas, neste caso, de classe. Segundo Bourdieu (2015, p. 108), "os efeitos do habitus jamais se encontram tão bem escondidos a não ser quando aparecem como o efeito direto das estruturas [...] porque são produzidos por agentes que são a estrutura 'feita homem'". Essa estrutura, aqui de classe e representada espacialmente, "faz" o homem/agente mostrando suas propriedades distintivas. Claramente, percebemos na ACM a associação diferenciada entre classes sociais e motivos para ingressar no ensino superior e essas associações podem ser explicadas pela teoria das classes sociais e da reprodução social do sistema de ensino de Bourdieu (2007; 2015). 
Figura 1: Mapa bidimensional indicando a associação entre classe social e motivo pela escolha do curso de graduação

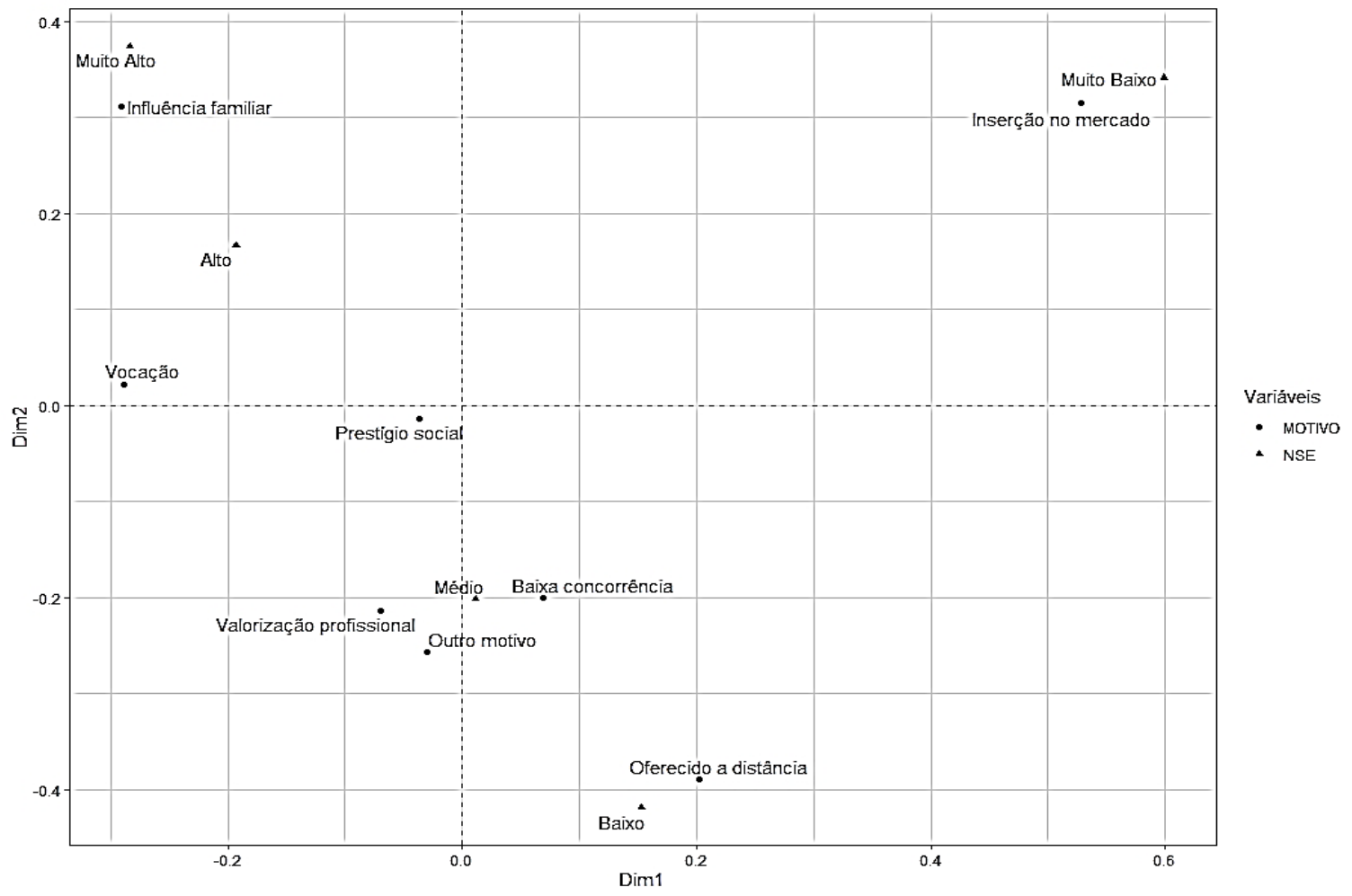

Fonte: Dados da pesquisa.

Do mapa, pode-se perceber que estudantes oriundos dos mais altos níveis socioeconômicos, Muito Alto e Alto, em geral, escolhem o curso de graduação por influência familiar ou por vocação. A influência familiar se justifica sociologicamente pelo fato de os pais destes estudantes terem feito uma graduação e estarem muito bem posicionados no mercado de trabalho, o que impacta diretamente na escolha da profissão dos filhos (Silva, 2010). Estudantes de elevado NSE indicarem a vocação como possível motivo para a escolha do curso de graduação é o reflexo do mito meritocrático veladamente difundido nas escolas (Bourdieu; Passeron, 2009).

A associação com a influência familiar na escolha do curso revela a força do habitus de classe e do capital cultural distintivo deste grupo cuja transmissão é, essencialmente, familiar. Essa relação familiar remete também à herança de patrimônio cultural e econômico que, segundo Bourdieu (2015, p. 106, grifos no original), "é um conjunto de direitos de preempção sobre o futuro, sobre as posições sociais passíveis de serem ocupadas e, por conseguinte, sobre as maneiras possíveis de ser homem". Quanto à vocação, é necessário, inicialmente, ressaltar a referência ao dom e a aptidão para o estudo que essa palavra carrega. Essas ideias foram refutadas há muitos anos pela teoria sociológica, pois, para Bourdieu (2015, p. 133), ao contrário do que sugerem, elas "dão testemunho da ignorância de que a 'aptidão' ou o 'dom' é também o produto de um investimento em tempo e em capital cultural". Por fim, ressaltamos que a opção das classes privilegiadas, pautada na vocação e na família, remetem a uma escolha mais natural, livre ou hedonista, pouco pragmática ou preocupada, direta e imediatamente, com a rentabilidade do diploma no mercado de trabalho. Parte dessa escolha se refere ao fato de que essas classes não têm a ascensão social como meta, uma vez que já se encontram no topo. Além disso, 
como afirma Bourdieu (2015, p. 105) "tais riscos nunca são assumidos a não ser quando se tem a certeza de nunca perder tudo ao tentar ganhar tudo", ou seja, quem detém maiores volumes de capitais pode correr riscos maiores, fazer escolhas mais ousadas e distanciadas de preocupações imediatas e pragmáticas.

De maneira distinta, os estudantes de NSE Médio, que pode ser entendida como uma classe média considerando a estratificação bourdiana, se relaciona fortemente com os motivos de valorização profissional e baixa concorrência. Quer dizer, a classe média faz a escolha pelo curso de graduação de forma bem pragmática, selecionando um curso com baixa concorrência e que ao mesmo tempo permita uma maior valorização profissional. A baixa concorrência nos permite levantar a hipótese de procura por instituições públicas, uma vez que no Brasil a maior parte das privadas realiza processos seletivos simbólicos. Além disso, para as frações de classe média que dependem mais do capital cultural, a escola tende a ser a única via de ascensão social. Portanto, esses dois fatores, mostram que há uma preocupação em obter uma rentabilidade máxima do diploma, por meio de duas estratégias educacionais (Bourdieu, 2015): 1) garantir o acesso ao Ensino Superior por meio da escolha por cursos, possivelmente gratuitos, com baixa concorrência; 2) optar por cursos com maior valorização social, mostrando um reconhecimento dos valores em jogo no sistema de ensino e no mercado de trabalho. Bourdieu (2015, p. 108) afirma que "a fração ascendente da pequena burguesia [...] distinguem-se sistematicamente do que deveriam ser teoricamente se dependessem apenas do capital econômico e/ou cultural", ou seja, trata-se de uma fração que não detém capital econômico suficiente para pagar por um curso de prestígio de Ensino Superior, mas detém capital cultural suficiente, principalmente na forma de informações sobre o sistema de ensino, para fazer escolhas mais rentáveis apesar da estratificação horizontal do ensino superior (Duru-Bellat, 2006; Bertoncelo, 2016; Crepalde; Silveira, 2016).

Os estudantes oriundos do NSE Baixo, em geral, escolhem o curso de graduação pelo fato de serem oferecidos a distância. Este resultado sugere que são indivíduos que buscam um título escolar superior por entenderem a sua importância e relevância social, porém, não podem participar de cursos presenciais, especialmente por possuírem trabalho fixo (Carvalho, 2014; Alcantara, 2016). Além disso, considerando que esses cursos tendem a oferecer um ensino de menor qualidade, que é desvalorizado no mercado de trabalho, nos parece coerente que ele atraia estudantes com baixo capital econômico e cultural.

Por fim, os pertencentes ao nível socioeconômico mais baixo, que são os estudantes de baixa renda e pais com baixo nível de escolarização, escolhem o curso de graduação pensando diretamente na sua inserção no mercado de trabalho. A transformação rápida da presença em um curso de graduação em inserção no mercado de trabalho faz com que os indivíduos busquem especialmente cursos de licenciatura, pela reconhecida carência de profissionais na área (Gatti, 2009). Essa escolha se relaciona com o fato de que as camadas populares não vislumbram "para os filhos um futuro diferente de seu próprio presente" (Bourdieu, 2015, p. 109). Portanto, embora estejam buscando o Ensino Superior e a ascensão social, que contraria suas tendências de manutenção de sua posição 
social, essas classes fazem investimentos que prometem um retorno mais rápido e uma conversão direta deste capital cultural institucionalizado, na forma de diploma, em capital econômico.

Infelizmente, Bourdieu (2015) nos lembra que essas escolhas das camadas menos favorecidas tendem a apresentar, por efeito da inércia de seu habitus, maiores chances de baixos retornos no mercado. Tratam-se de investimentos menos arriscados, em ensino a distância e cursos voltados para o mercado de trabalho atual, que, portanto, geram menos lucros. Em geral, quando as classes menos favorecidas enxergam uma possibilidade de acesso, essa porta aberta revela que a oportunidade oferecida não é mais tão valorizada quanto antes. O diploma do Ensino Superior tende a ser cada vez mais questionado quanto à sua rentabilidade, mesmo em países mais ricos que o Brasil, e a realidade que observamos aqui, por exemplo no caso dos egressos do curso de Matemática, é a atuação em empregos que sequer exigem essa qualificação (Beltrão; Mandarino, 2014).

\section{Considerações finais}

Neste artigo investigamos a associação entre o pertencimento de classe e os motivos que levaram estudantes a escolher o curso de nível superior. Nos pautamos em Bourdieu (2015, p. 106-107) para compreender "a distribuição, entre as classes, das chances de acesso às diferentes ordens do sistema de ensino" e "os diferentes privilégios que ele transmite". Nesse processo, a causalidade do provável atua, como demonstramos a partir da análise dos motivos que influenciaram os estudantes na escolha do curso de nível superior na manutenção das desigualdades. Quando os estudantes menos favorecidos optam por cursos a distância que prometem uma inserção mais rápida no mercado, tendem a manter suas posições sociais desfavorecidas. Portanto, há uma "colaboração insensivelmente extorquida das classes despossuídas", pois pela causalidade do provável elas "tendem a estabelecer uma proporção entre seus investimentos escolares e os lucros prometidos, portanto, antecipar os veredictos do sistema" (Bourdieu, 2015, p. 107).

Neste trabalho nos propomos a contribuir com as discussões de pesquisas focadas no Ensino Superior brasileiro a partir da análise das diferenciações e desigualdades das classes sociais em relação aos motivos que levam à escolha de um curso de graduação. Como perspectiva futura de expansão desta pesquisa, outras variáveis dos microdados do ENADE podem ser utilizadas para investigações das desigualdades e diferenciações de classes sociais, como o principal motivo para a escolha da Instituição de Ensino Superior, a frequência de leitura dos estudantes, o tempo dedicado ao trabalho e aos estudos ou, ainda, quais as pessoas que mais contribuíram para cursar a graduação. Ademais, ações que tenham contribuído para a permanência dos estudantes na graduação, considerando o cenário de forte evasão principalmente nos cursos de ciências ditas exatas, também podem ser investigadas a partir dos dados do ENADE.

\section{Referências}

ALCANTARA, Juliana. Ensino a distância: conheça o perfil dos estudantes que se dão bem nesse modelo. Extra. 23 dez. 2016. Disponível em: http://glo.bo/3ntwKkY. Acesso em: 15 jun. 2020. 
ALFANO, Bruno. "O Enem e uma competição. Ficou mais difícil para todo mundo", afirma Weintraub, mantendo datas do Enem. O Globo. 17 abr. 2020. Disponível em: https://glo.bo/2JZ9mNK. Acesso em: 20 abr. 2020.

BELTRÃO, Kaizôlwakami; MANDARINO, Mônica Cerbella Freire. Evidências do ENADE: mudanças no perfil do matemático graduado. Ensaio: Avaliação e Políticas Públicas em Educação, v. 22, n. 84, p. 733-754, 2014.

BERTOLIN, Júlio; MARCON, Telmo. O (des)entendimento de qualidade na Educação Superior brasileira: das quimeras do provão e do ENADE à realidade do capital cultural dos estudantes. Avaliação, v. 20, n. 1, p. 105-122, 2015.

BERTONCELO, Edison. Classes sociais, cultura e educação. Novos Estudos, v. 104, p. 159-175, 2016.

BONAMINO, Alicia; SOUZA, Sandra Zákia. Três gerações de avaliação da educação básica no Brasil: interfaces com o currículo da/na escola. Educação e Pesquisa, v. 38, n. 2, p. 373-388, 2012.

BOURDIEU, Pierre. Esboço de uma teoria da prática. In: ORTIZ, Renato (Ed.). Pierre Bourdieu: Sociologia. São Paulo: Ática, 1983, p.46-81.

BOURDIEU, Pierre. A distinção: crítica social do julgamento. São Paulo: Edusp; Porto Alegre: Zouk, 2007.

BOURDIEU, Pierre. Futuro de classe e causalidade do provável. In: NOGUEIRA, Maria Alice; CATANI, Afrânio (Orgs.). Escritos de educação. Petrópolis: Vozes, 2015, p.89-141.

BOURDIEU, Pierre; PASSERON, Jean-Claude. A reprodução: elementos para uma teoria do sistema de ensino. Petrópolis: Vozes, 2009.

BRITO, Marcia Regina de. ENADE 2005: perfil, desempenho e razão da opção dos estudantes pelas licenciaturas. Avaliação, v. 12, n. 3, p. 401-433, 2007.

BRITO, Marcia Regina de; O SINAES e o ENADE: da concepção à implantação. Avaliação, v. 13, n. 3, p. 841-850, 2008.

BRASIL. Lei n. 10.861, de 14 de abril de 2004: institui o Sistema Nacional de Avaliação da Educação Superior SINAES e dá outras providências. Gov.br. 14 abr. 2004. Disponível em: https://bit.ly/3miHu3X. Acesso em: 20 jun. 2020.

CANAN, Silvia Regina; ELOY, Vanessa Taís. Políticas de avaliação em larga escala: o ENADE interfere na gestão dos cursos? Práxis Educativa, v. 11, n. 3, p. 621-640, 2016.

CARVALHO, Bruna. Ensino a distância: limites e possibilidades na formação de professores. 284f. Mestrado em Educação Escolar pela Universidade Estadual Paulista Júlio de Mesquita Filho. Araraquara, 2014.

CREPALDE, Neyson João Batista Filho; SILVEIRA, Leonardo Souza. Desempenho universitário no Brasil: estudo sobre desigualdade educacional com dados do Enade 2014. Revista Brasileira de Sociologia, v. 4, n. 7, p. 211238, 2016.

DURU-BELLAT, Marie. L'inflationscolaire: les désillusions de la méritocratie. Paris: Éditions du Seuil et La République des Idées, 2006.

FELDMAN, Taise; SOUZA, Osmar. A governamentalidade e o Exame Nacional de Desempenho de Estudantes ENADE. Avaliação, v. 21, n. 3, p. 1017-1032, 2016.

GATTI, Bernardete (Org.). Atratividade da carreira docente no Brasil: relatório preliminar. São Paulo: Fundação Carlos Chagas, 2009.

GREENACRE, Michael. Correspondence analysis in practice. London: Chapman and Hall/CRC, 2017.

GUALBERTO, Lucas; RODRIGUES, André. Impacto do trabalho no desempenho dos licenciandos no ENADE. Ensenãnza de las Ciencias, v. 35, n. 3, p. 2675-2680, 2017.

HEY, Ana Paula. Esboço de uma sociologia do campo acadêmico: a Educação Superior no Brasil. São Carlos: EdUFSCar, 2008.

INEP. Exame Nacional de Desempenho dos Estudantes (ENADE). Inep. 2020a. Disponível em: https://bit.ly/38bwQHc. Acesso em: 30 jan. 2020.

INEP. Microdados. Inep. 2020b. Disponível em: https://bit.ly/3qZPmed. Acesso em: 25 abr. 2020.

LEMOS, Karinne Custódio Silva; MIRANDA, Gilberto José. Alto e baixo desempenho no ENADE: que variáveis explicam? Revista Ambiente Contábil, v. 7, n. 2, p. 101-118, 2015.

LIMA, Priscila da Silva Neves et al. Análise de dados do Enade e Enem: uma revisão sistemática da literatura. Avaliação, v. 24, n. 1, p. 89-107, 2019. 
KLUGER, Elisa. Análise de correspondências múltiplas: fundamentos, elaboração e interpretação. Bib, v. 86, n. 2, p. 68-97, 2018.

MASSI, Luciana; CARVALHO, Helena; GIORDAN, Marcelo. Perfil socioformativo dos orientadores, heterogeneidade e hierarquia social na área de ensino da CAPES. Investigações em Ensino de Ciências, v. 25, n. 1, p. 421-432, 2020.

NASCIMENTO, Matheus Monteiro; CAVALCANTI, Cláudio; OSTERMANN, Fernanda. Uma busca por questões de Física do ENEM potencialmente não reprodutoras das desigualdades socioeconômicas. Revista Brasileira de Ensino de Física, v. 40, n. 3, p. 1-18, 2018.

PEROSA, Graziela Seronni; LEBARON, Frédéric; LEITE, Cristiane Kerches da Silva. O espaço das desigualdades educativas no município de São Paulo. Pro-Posições, v. 26, n. 2, p. 99-118, 2015.

SILVA, Mariléia Maria da. Redes de relações sociais e acesso ao emprego entre os jovens: 0 discurso da meritocracia em questão. Educação \& Sociedade, v. 31, n. 110, p. 243-260, 2010.

SOARES, Francisco José et al. Avaliação da Educação Superior no Brasil - do Provão ao ENADE: um estudo meta-avaliativo. Meta: Avaliação, v. 10, n. 31, p. 22-42, 2018.

SOUZA, Jessé de. A classe média no espelho: sua história, seus sonhos e ilusões, sua realidade. Rio de Janeiro: Estação Brasil, 2018.

TEAM, R Core. $R$ language definition. Vienna: $R$ foundation for statistical computing, 2000.

VERHINE, Robert Evan; DANTAS, Lys Maria Vinhares; SOARES, José Francisco. Do Provão ao ENADE: uma análise comparativa dos exames nacionais utilizados no Ensino Superior Brasileiro. Ensaio: Avaliação e Políticas Públicas em Educação, v. 14, n.52, p. 291-310, 2006.

WAINER, Jacques; MELGUIZO, Tatiana. Políticas de inclusão no Ensino Superior: avaliação do desempenho dos alunos baseado no Enade de 2012 a 2014. Educação e Pesquisa, v. 44, n. 1, p. 1-15, 2018. 